Article

\title{
Influence of Lithium Carbonate and Sodium Carbonate on Physical and Elastic Properties and on Carbonation Resistance of Calcium Sulphoaluminate-Based Mortars
}

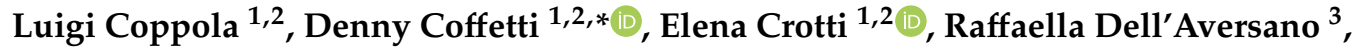 \\ Gabriele Gazzaniga ${ }^{1}$ and Tommaso Pastore ${ }^{1,2}$ (D) \\ 1 Department of Engineering and Applied Sciences, University of Bergamo, 24129 Bergamo, Italy; \\ luigi.coppola@unibg.it (L.C.); elena.crotti@unibg.it (E.C.); gabriele.gazzaniga@unibg.it (G.G.); \\ tommaso.pastore@unibg.it (T.P.) \\ 2 UdR "Materials and Corrosion", Consorzio INSTM, 50121 Florence, Italy \\ 3 Department of Engineering, University of Campania "Luigi VanvitellI", 81031 Aversa, Italy; \\ raffaella.dellaversano@unicampania.it \\ * Correspondence: denny.coffetti@unibg.it; Tel.: +39-035-2052054
}

Received: 27 November 2019; Accepted: 20 December 2019; Published: 25 December 2019

\begin{abstract}
In this study, three different hardening accelerating admixtures (sodium carbonate, lithium carbonate and a blend of sodium and lithium carbonates) were employed to prepare calcium sulphoaluminate cement-based mortars. The workability, setting times, entrapped air, elasto-mechanical properties such as compressive strength and dynamic modulus of elasticity, free shrinkage, water absorption and carbonation rate were measured and mercury intrusion porosimetry were also performed. Experimental results show that a mixture of lithium carbonate and sodium carbonate acts as a hardening accelerating admixture, improving the early-age strength and promoting a remarkable pore structure refinement. Finally, sodium carbonate also reduces the water absorption, the carbonation rate and the shrinkage of mortars without affecting the setting times and the workability.
\end{abstract}

Keywords: calcium sulphoaluminate cement; supplementary cementitious materials; carbonation; lithium carbonate; sodium carbonate

\section{Introduction}

During the last years, the construction sector has been looking for some solutions able to reduce the environmental impacts typical of building materials, particularly related to the use of Portland cement, which requires a considerable amount of raw non-renewable natural resources and a great energy input during the clinker production [1].

Several strategies have been proposed by different authors [2,3] aimed at improving the sustainability of cementitious materials: reduction of the greenhouse gases emission by using alternative fuels $[4,5]$, replacement of Portland cement (OPC) clinker with low-carbon supplementary cementitious materials (SCM) [6-8], utilization of wastes $[9,10]$ and development of alternative binders (such as alkali-activated materials) [11,12].

One of the most interesting and simple ways to reduce the environmental impact of mortars and concretes is using calcium sulphoaluminate cement (CSA) as a partial replacement of ordinary Portland cement [13]. For this reason, ternary mixtures of OPC, CSA and calcium sulphate (gypsum, anhydrite or hemihydrate) were largely investigated and properties like rapid setting times, fast 
strength development and low shrinkage have been appreciated [14-16]. However, some aspects of CSA cement, i.e., the effect of admixtures, have not been exhaustively investigated yet.

Most studies about admixtures in calcium sulphoaluminate cements deal with the influence of superplasticizers [17-21], shrinkage reducing admixtures [22-24] and retarders [16,18,25-27] but only a few papers focus on the use of hardening accelerating admixtures. Perà et al. [28] highlighted the feasibility of using lithium chloride and lithium carbonate to accelerate the hydration of CSA-based mixtures thanks to the formation of Li-rich aluminum hydroxides. Cau Dit Coumes et al. also investigated the influence of Li-based admixtures (alone [29] or in combination with sodium borate [30]) on the hydration of CSA cements, confirming that the acceleration effect is related to the very rapid precipitation of amorphous $\mathrm{Li}$-containing $\mathrm{Al}(\mathrm{OH})_{3}$. However, there is a lack of knowledge regarding the physico-mechanical properties and durability issues of CSA-based mortars and concretes manufactured using Li-based hardening accelerating admixtures. On the other hand, to date, no experimental data have been published concerning the use of sodium-based accelerators in CSA-based mixtures.

For the abovementioned reasons, the purpose of the present work is to evaluate the influence of hardening accelerating admixtures based on sodium and lithium carbonate on the rheological, physical, elasto-mechanical properties of mortars manufactured with calcium sulphoaluminate cement.

\section{Materials and Methods}

Three different mortars based on calcium sulphoaluminate were investigated as reported in Table 1 in accordance with a previous work [31]. In particular, a traditional mortar (hereafter referred to as TM) containing CSA clinker, Portland cement (OPC, according to EN 197-1) and technical grade anhydrite (CS) was produced. Additionally, two sustainable CSA-based mortars (hereafter referred to as SM 1 and SM 2, respectively) in which OPC is totally replaced by supplementary cementitious materials (SCMs, ground granulated blast furnace slag (GGBFS) according to EN 1516-7 and low calcium fly ash (FA) according to EN 450-1) and hydrated lime CL-90S class (CH, according to EN 459-1) were manufactured. Physical properties of the binders and the supplementary cementitious materials used are reported in Table 2. A set retarding admixture (0.8 wt.\% mass of binder) based on tartaric acid (TA) was used to delay the initial set of mortars [26]. Lithium carbonate (LC) and sodium carbonate (SC) were also added to the mix as hardening accelerating admixtures up to $4 \%$ by binder mass in accordance with [32]. Finally, a natural siliceous sand with a maximum size equal to $2.5 \mathrm{~mm}$ was used (Figure 1).

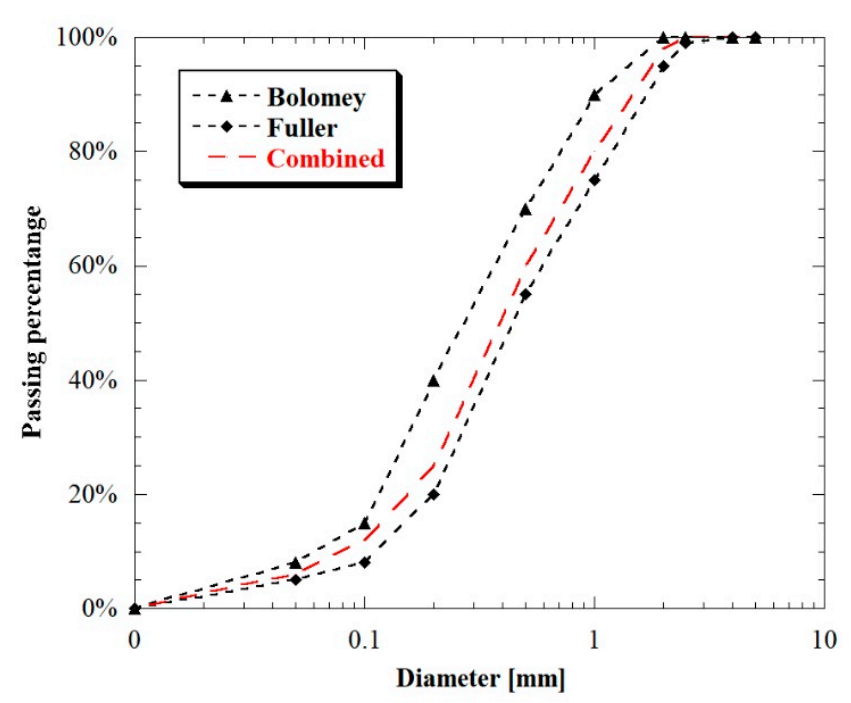

Figure 1. Granulometry of aggregates.

The water/binder ratio and binder/sand ratio were kept constant at 0.53 and 3.0, respectively. 
Table 1. Composition of mortars (TM: traditional CSA-based mortar, SM: sustainable CSA-based mortars, SC: sodium carbonate, LC: lithium carbonate).

\begin{tabular}{|c|c|c|c|c|c|c|c|c|c|c|c|c|}
\hline $\begin{array}{c}\text { Composition } \\
{\left[\mathrm{kg} / \mathrm{m}^{3}\right]}\end{array}$ & 芯 & ט. & إن & $\begin{array}{l}\infty \\
\mathbb{1} \\
0 \\
0 \\
0\end{array}$ & 左 & 焉 & $\begin{array}{l}\dot{60} \\
\dot{0} 0 \\
<\end{array}$ & $\frac{\grave{J}}{3}$ & $\varangle$ & U & $\underset{⿶}{\cup}$ & 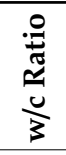 \\
\hline TM & 192 & 192 & 96 & & & & 1440 & 255 & 3.8 & & & 0.53 \\
\hline TM-SC & 192 & 192 & 96 & & & & 1440 & 255 & 3.8 & 19.2 & & 0.53 \\
\hline TM-LC & 192 & 192 & 96 & & & & 1440 & 255 & 3.8 & & 19.2 & 0.53 \\
\hline TM-SC-LC & 192 & 192 & 96 & & & & 1440 & 255 & 3.8 & 9.6 & 9.6 & 0.53 \\
\hline SM 1 & 192 & & 96 & 168 & & 24 & 1440 & 255 & 3.8 & & & 0.53 \\
\hline SM 1-SC & 192 & & 96 & 168 & & 24 & 1440 & 255 & 3.8 & 19.2 & & 0.53 \\
\hline SM 1-LC & 192 & & 96 & 168 & & 24 & 1440 & 255 & 3.8 & & 19.2 & 0.53 \\
\hline SM 1-SC-LC & 192 & & 96 & 168 & & 24 & 1440 & 255 & 3.8 & 9.6 & 9.6 & 0.53 \\
\hline SM 2 & 192 & & 96 & & 168 & 24 & 1440 & 255 & 3.8 & & & 0.53 \\
\hline SM 2-SC & 192 & & 96 & & 168 & 24 & 1440 & 255 & 3.8 & 19.2 & & 0.53 \\
\hline SM 2-LC & 192 & & 96 & & 168 & 24 & 1440 & 255 & 3.8 & & 19.2 & 0.53 \\
\hline SM 2-SC-LC & 192 & & 96 & & 168 & 24 & 1440 & 255 & 3.8 & 9.6 & 9.6 & 0.53 \\
\hline
\end{tabular}

Table 2. Physical properties of binders.

\begin{tabular}{ccccccc}
\hline & OPC & CSA & CS & CH & GGBFS & FA \\
\hline $\mathrm{D}_{50}[\mu \mathrm{m}]$ & 5.19 & 8.18 & 2.93 & 3.00 & 5.48 & 11.1 \\
Specific surface $\left[\mathrm{cm}^{2} / \mathrm{g}\right]$ & 3175 & 2722 & 4837 & 4678 & 3049 & 2283 \\
Specific mass $\left[\mathrm{kg} / \mathrm{m}^{3}\right]$ & 3150 & 2650 & 2670 & 2120 & 2730 & 2010 \\
\hline
\end{tabular}

The workability test by flow table described in EN 1015-3 was conducted on all the fresh mortars over time. In particular, the consistency was measured after the mixing procedure and the pot-life, corresponding to the time during which workability by flow table is higher than $140 \mathrm{~mm}$, was also determined. Furthermore, fresh mortar specific mass and entrapped air were also measured in accordance with EN 1015-6 and EN 1015-7, respectively.

The mixtures were molded into $40 \mathrm{~mm} \times 40 \mathrm{~mm} \times 160 \mathrm{~mm}$ specimens, demolded after $24 \mathrm{~h}$ and cured in a climatic chamber at $20{ }^{\circ} \mathrm{C}$ and $60 \%$ R.H. until tests (Table 3) in order to optimize the strength development in accordance with findings of Coppola et al. [33] concerning the curing condition of CSA-based mixtures. Specific mass at hardened state, determined by weighing the specimen before mechanical test, and compressive strength were measured at 1, 7, 28, 120 and 150 days according to EN 1015-11 and drying shrinkage was evaluated in accordance with EN 12617-4 up to 150 days. Furthermore, dynamic modulus of elasticity $\left(E_{d}\right)$ was measured by means of Ultrasonic Digital Indicator Tester at 1, 7, 28, 120 and 150 days (EN 12504-4). Then, pore size distribution and density of the specimens were determined by means of mercury intrusion porosimetry (MIP) using Thermo Pascal 140 and 440. The MIP mortar samples (three specimens for each mortars) were dried in oven at $40{ }^{\circ} \mathrm{C}$ for $24 \mathrm{~h}$ and tested after 28 days from casting. Approximately $1 \mathrm{~g}$ of mortar was first intruded to a mercury pressure, $\mathrm{P}_{\mathrm{Hg}}$, of $395 \mathrm{kPa}$ on the Pascal 140, then the sample was moved to the Pascal 440 and intruded to $200 \mathrm{MPa}$. Moreover, the depth of natural carbonation (specimens stored in air) was measured by a colorimetric test using phenolphthalein as $\mathrm{pH}$ indicator, according to EN 14630 up to 150 days. Finally, the capillary water absorption coefficient (AC) was estimated in accordance with EN 13057. 
Table 3. Specimens manufactured for each mortar.

\begin{tabular}{cccc}
\hline Test & Ages & Format Specimen & Note \\
\hline $\begin{array}{c}\text { Compressive strength } \\
\text { Specific mass } \\
\text { Elastic modulus }\end{array}$ & $1,7,28,120,150$ days & $\begin{array}{c}\text { Beam } \\
40 \times 40 \times 160 \mathrm{~mm}\end{array}$ & Three specimens for each age \\
\hline Free shrinkage & Up to 150 days & Beam & Three specimens for each age \\
\hline Mercury intrusion (MIP) & 28 days & Fragment $1 \mathrm{~g}$ & Three specimens \\
\hline Natural carbonation & Up to 150 days & $\begin{array}{c}\text { Beam } \\
40 \times 40 \times 160 \mathrm{~mm}\end{array}$ & Two specimens for each age \\
\hline Water absorption & 28 days & Beam & Three specimens for each age \\
\hline
\end{tabular}

\section{Results}

\subsection{Fresh Properties}

The addition of lithium carbonate and sodium carbonate does not produce any abnormal air entrapment or variation in specific mass at fresh state (Table 4). Moreover, results show that the addition of LC and SC has different effects on mortar consistency. In particular, a small increase in workability was observed in mortars manufactured with sodium carbonate admixtures or SC-LC blends while no variations on workability were detected by using LC regardless of the binder used.

Lithium carbonate caused a sharp reduction in pot-life of mortars, independently of the binder used (Figure 2). In particular, LC seems to completely neutralize the retarding effect promoted by tartaric acid [26], decreasing the pot-life of the mixtures to a value close to $30 \mathrm{~min}$. On the contrary, mortars containing SC showed a very slight decrease in pot-life. Finally, the combination of SC and LC determined a reduction of pot-life approximately equal to $30 \%$, independent of the binder.

Table 4. Properties of mortars at fresh and hardened state.

\begin{tabular}{|c|c|c|c|c|}
\hline & \multirow{2}{*}{ Workability [mm] } & \multirow{2}{*}{ Air Content [\%] } & \multicolumn{2}{|c|}{ Specific Mass $\left[\mathrm{kg} / \mathrm{m}^{3}\right]$} \\
\hline & & & Fresh State & Hardened State \\
\hline TM & 165 & 4.9 & 2195 & 2175 \\
\hline TM-SC & 180 & 4.9 & 2200 & 2185 \\
\hline TM-LC & 170 & 5.0 & 2190 & 2170 \\
\hline TM-SC-LC & 180 & 4.8 & 2190 & 2170 \\
\hline SM 1 & 150 & 4.8 & 2190 & 2160 \\
\hline SM 1-SC & 160 & 5.0 & 2190 & 2170 \\
\hline SM 1-LC & 150 & 5.1 & 2195 & 2170 \\
\hline SM 1-SC-LC & 170 & 4.8 & 2185 & 2170 \\
\hline SM 2 & 160 & 4.8 & 2180 & 2165 \\
\hline SM 2-SC & 180 & 4.9 & 2185 & 2170 \\
\hline SM 2-LC & 160 & 5.0 & 2175 & 2165 \\
\hline SM 2-SC-LC & 175 & 4.9 & 2175 & 2160 \\
\hline
\end{tabular}




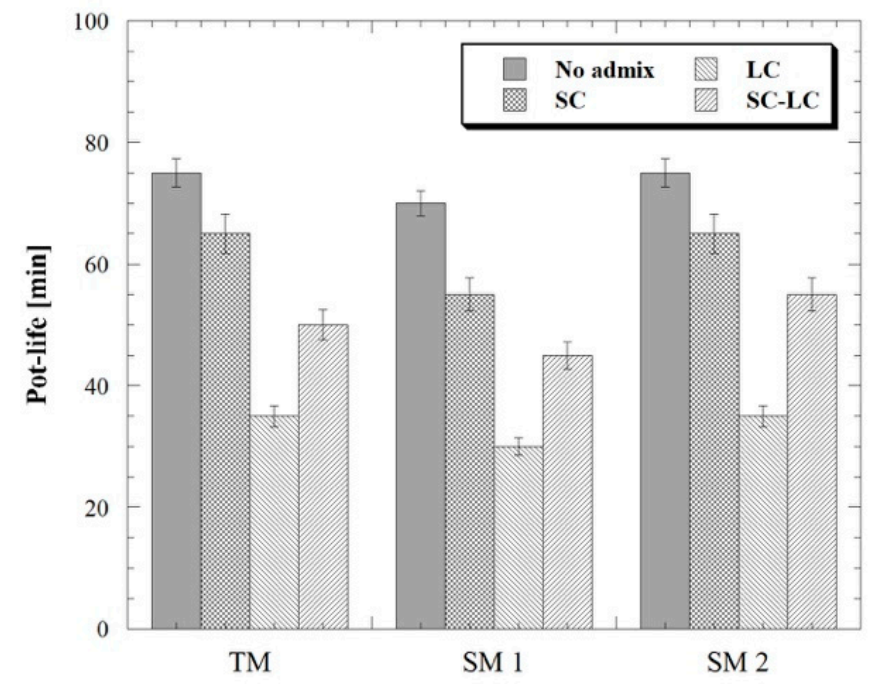

Figure 2. Pot-life of fresh mixtures.

\subsection{Mercury Intrusion}

The average results of mercury intrusion porosimetry (MIP) are reported in Figure 3. According to results reported by Bernardo et al. [34], the distribution of pore size is bimodal for all the CSA-based mixtures with the first threshold close to $100-200 \mathrm{~nm}$ while the second threshold pore size is in the range of $50-90 \mathrm{~nm}$.

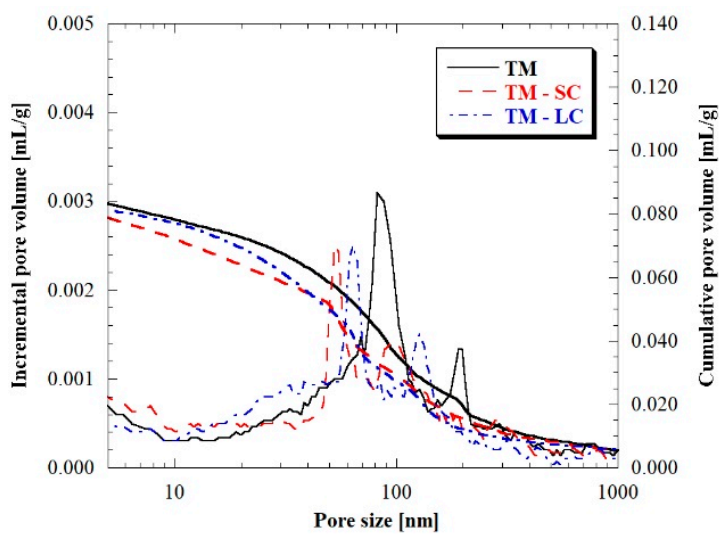

(a)

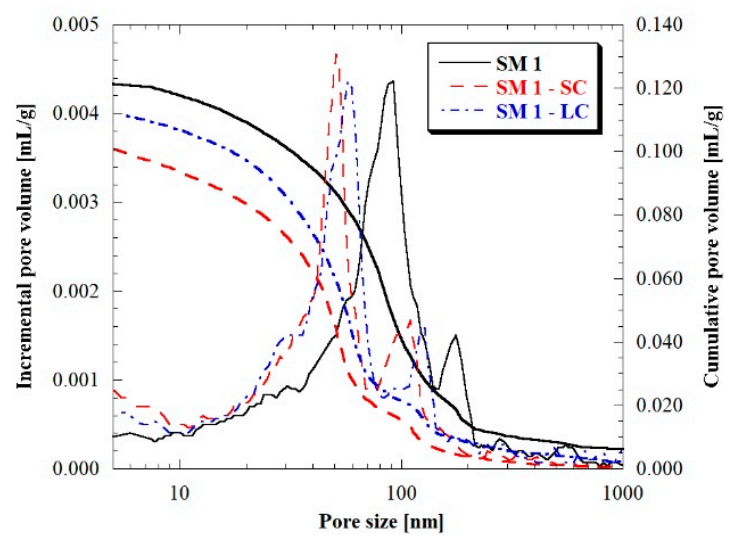

(b)

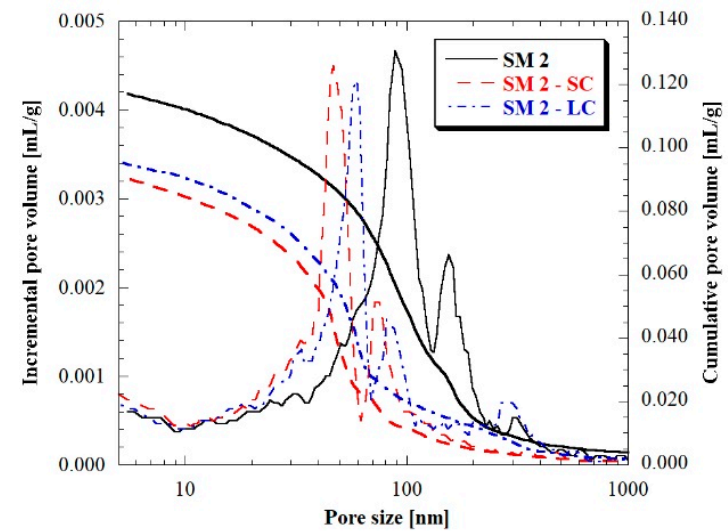

(c)

Figure 3. Intruded Hg volume vs. pore size for mortar TM (a), SM1 (b) and SM2 (c) with different admixtures (cumulative values in thick line). 
The total replacement of Portland cement with supplementary cementitious materials strongly influences the total porosity with negligible changes in the average pore size. In particular, for mortars manufactured without hardening accelerating admixtures, the porosity varied from $18.5 \%$ for $\mathrm{TM}$ to $23.9 \%$ and $23.6 \%$, respectively, for SM1 and SM2, whereas the first and second threshold pore radius are close to $200 \mathrm{~nm}$ and $90 \mathrm{~nm}$, respectively. The addition of SC and LC admixtures determines a pore structure refinement for all mixes with a reduction of the total porosity and a shift both in the first threshold pore size from $200 \mathrm{~nm}$ to $150 \mathrm{~nm}$ (LC) or $100 \mathrm{~nm}$ (SC) and in the second threshold pore radius from 90 to $60 \mathrm{~nm}$ (LC) or $50 \mathrm{~nm}$ (SC). In particular, the effectiveness of sodium carbonate (SC) in pore structure refinement is higher than that of lithium carbonate (LC).

\subsection{Elasto-Mechanical Properties}

In Figure 4 are reported the compressive strength developments of mortars manufactured with different hardening accelerating admixtures. Results indicated that lithium carbonate and sodium carbonate affect the elasto-mechanical properties of both TM and SM. The compressive strength at early ages ( $24 \mathrm{~h}$ and 7 days) is strongly improved by the addition of SC and LC admixtures. In particular, compressive strength approximately doubled with respect to the reference mortars manufactured without hardening accelerating admixtures, regardless the nature of alkaline ions ( $\mathrm{Li}$ or $\mathrm{Na}$ ) present in the admixtures. Sodium carbonate promotes the formation of gyrolite which is responsible for the acceleration of setting times as reported by Reddy et al. [35] and the improvement of compressive strength at early ages [36]. On the other hand, lithium carbonate addition is responsible for the precipitation of lithium aluminate hydrate $\mathrm{LiAl}_{2}(\mathrm{OH})_{7} \cdot 2 \mathrm{H}_{2} \mathrm{O}$ which serves as nucleation site for aluminum hydroxide precipitation that accelerates the whole hydration process and promotes the production of ettringite, the main hydration product of CSA cements $[29,30,37]$.

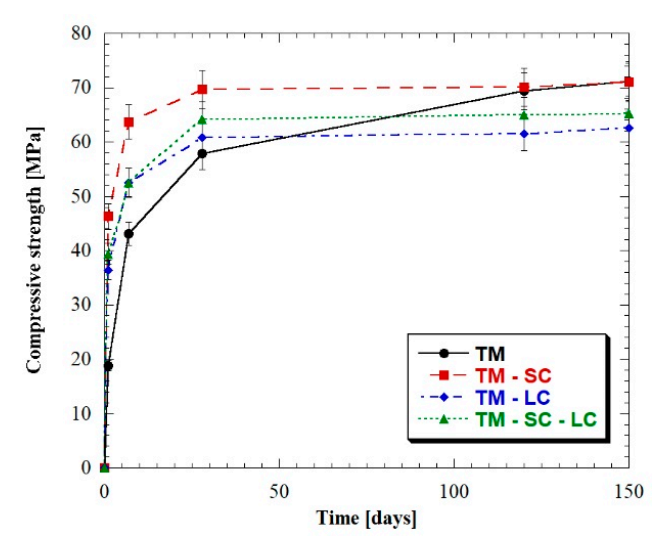

(a)

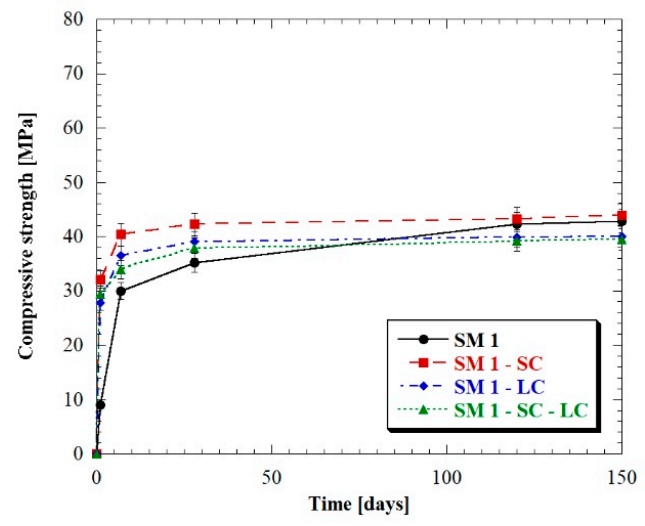

(b)

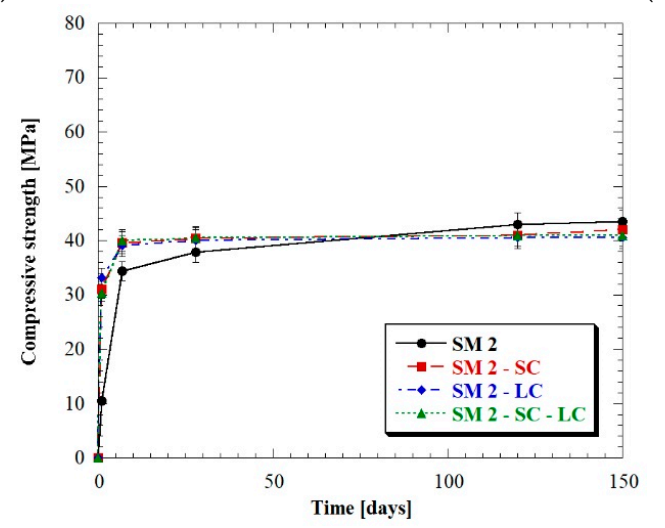

(c)

Figure 4. Compressive strength development of mortar (a) TM, (b) SM1 and (c) SM2 with different admixtures. 
However, at long ages, compressive strength of SM1 and SM2 mortars produced with or without hardening accelerating admixtures was similar. In detail, SM1 and SM2 mortars were characterized by compressive strength value close to $40 \mathrm{MPa}$ after 150 days similarly with [26]. On the contrary, the addition of sodium carbonate on TM mortar did not produce variations on compressive strength after 120 and 150 days while the use of lithium carbonate, alone or in combination with sodium carbonate, caused strength losses at long ages approximately equal to $10 \%$.

Figure 5 reports the dynamic modulus of elasticity of mortars after 24 h, 28 days and 150 days normalized respect to the mortars manufactured without admixtures. The role of hardening accelerating admixtures is evident also in the elastic modulus development. Similar to compressive strength, the addition of SC and/or LC on TM, SM1 and SM2 strongly increases the dynamic modulus of elasticity at $24 \mathrm{~h}$ with growing close to $20-40 \%$ respect to no-admixed mortars. However, this effect disappears already after 28 days when elastic modulus results quite similar (90-110\%) to that of mortars manufactured without hardening accelerating admixtures.

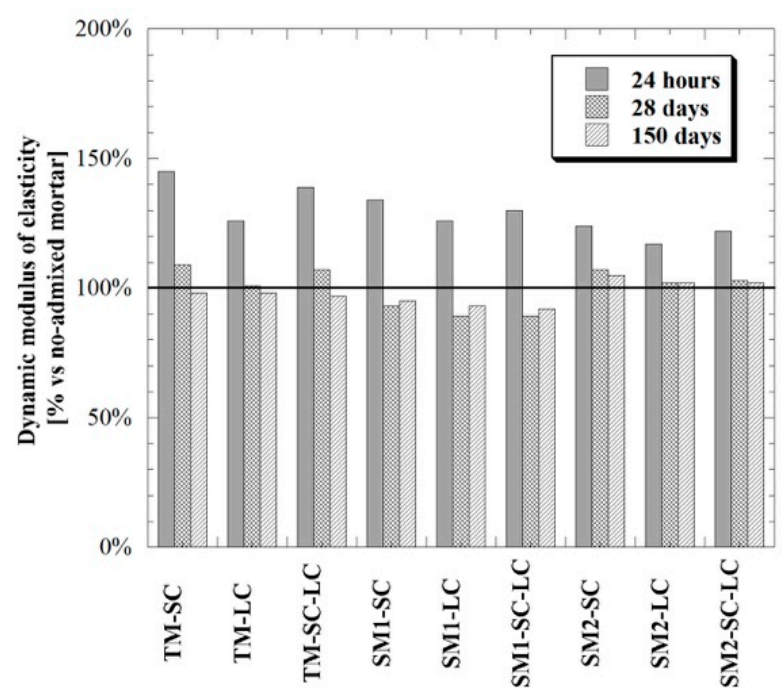

Figure 5. Elastic modulus of mortars with different admixtures normalized respect to mortars manufactured without admixtures.

\subsection{Free Shrinkage}

Free shrinkage of traditional and sustainable mortars is shown in Figure 6. The addition of hardening accelerating admixtures strongly influenced the shrinkage of CSA-based mortars. The use of LC, alone or with SC, increased the free shrinkage of both TM and SMs up to $100 \%$. In particular, traditional mortar without admixtures was characterized by shrinkage equal to $200 \mu \mathrm{m} / \mathrm{m}$ after 150 days while TM-LC and TM-SC-LC reached values close to 380 and $280 \mu \mathrm{m} / \mathrm{m}$, respectively. Also, mortars were influenced by the lithium-based admixtures, reaching shrinkage ranging from 350 to $450 \mu \mathrm{m} / \mathrm{m}$. On the contrary, the addition of SC allows to reduce by half the shrinkage of CSA-based mortars, regardless of the binder probably due to the greater amount of ettringite produced during hydration as reported by Li et al. [38]. 


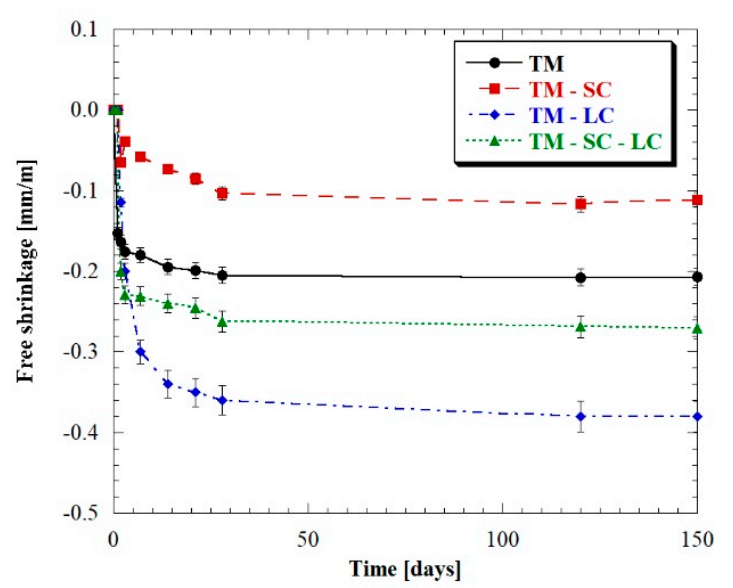

(a)

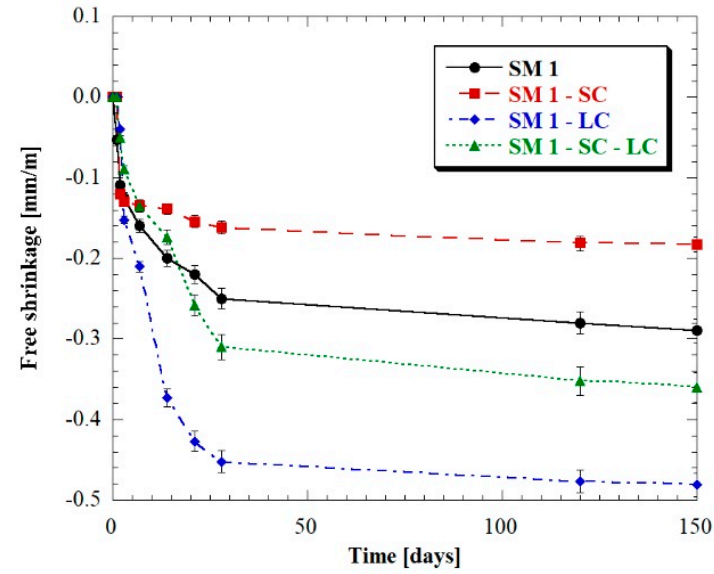

(b)

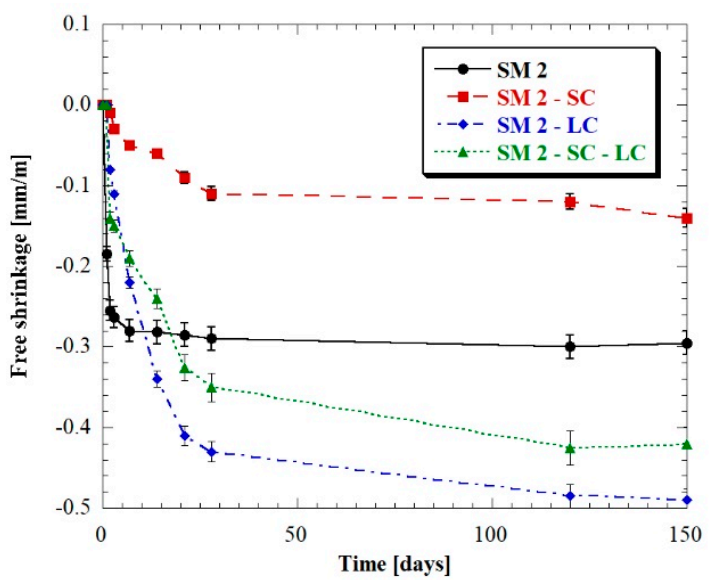

(c)

Figure 6. Free shrinkage of mortar (a) TM, (b) SM1 and (c) SM2 with different admixtures.

\subsection{Water Absorption}

Capillary water absorption coefficient (AC) of mortars was strongly influenced by the addition of sodium carbonate and the binder used (Table 5). The total substitution of Portland cement with supplementary cementitious materials and hydrated lime increased the capillary water absorption coefficient by about $220 \%$ due to the higher total porosity of sustainable mixtures SM respect to traditional mortar TM. Moreover, the use of SC admixture allows to obtain a less porous binder matrix characterized by a lower water absorption coefficient $(-25 \%)$ respect to those of LC-based or no-admixed mortars, regardless of the binder used.

Table 5. Capillary water absorption coefficient (AC) of mortars with different admixtures.

\begin{tabular}{ccccc}
\hline \multirow{2}{*}{$\begin{array}{c}\text { Capillary Water Absorption } \\
\text { Coefficient }\left[\mathbf{k g} / \mathbf{m}^{\mathbf{2}} \mathbf{h}^{\mathbf{0 . 5}}\right]\end{array}$} & - & SC & LC & SC-LC \\
\cline { 2 - 5 } & 0.854 & 0.632 & 0.753 & 0.741 \\
TM & 1.758 & 1.391 & 1.680 & 1.731 \\
SM1 & 1.806 & 1.346 & 1.703 & 1.798 \\
SM2 &
\end{tabular}

\subsection{Carbonation}

Figure 7 shows the natural carbonation depth of mortars over time. TM mortars (containing OPC) were characterized by lower carbonation than SM mortars (containing SCMs) due to their lower porosity and the remarkable $\mathrm{CO}_{2}$ buffer capacity of portlandite deriving from the OPC hydration. 
In particular, after 150 days, the TM reached carbonation depth close to $11 \mathrm{~mm}$ while SM were characterized by a carbonation depth higher than $14 \mathrm{~mm}$.

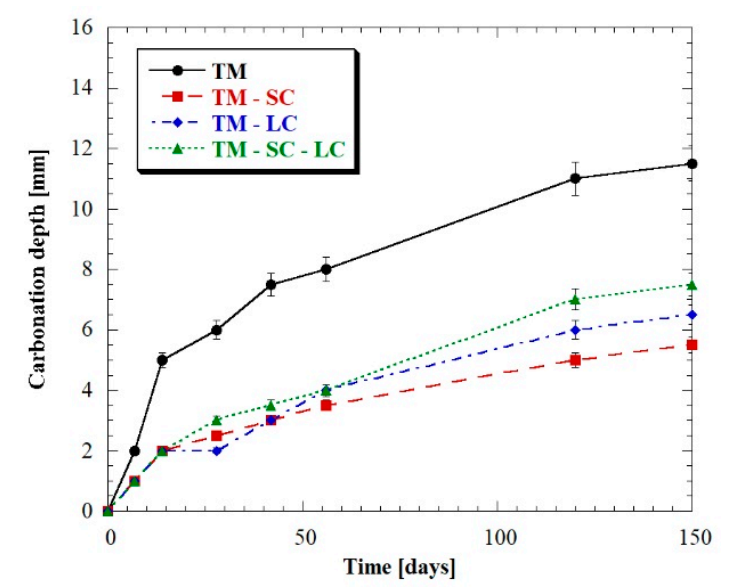

(a)

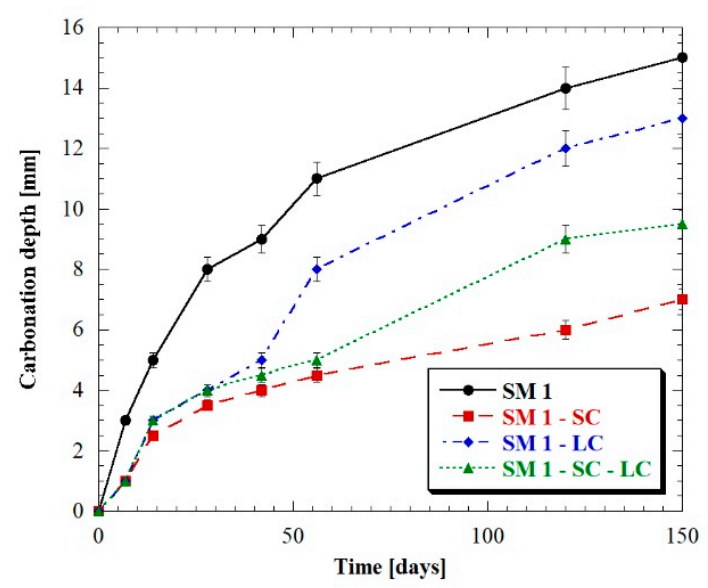

(b)

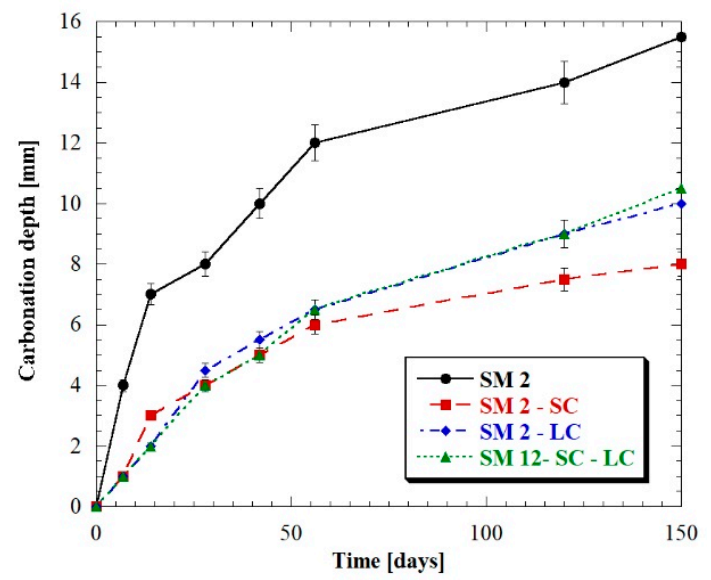

(c)

Figure 7. Carbonation of mortar (a) TM, (b) SM1 and (c) SM2 with different admixtures.

A beneficial effect against the carbonation is given by the addition of hardening accelerating admixtures. In fact, lithium carbonate and sodium carbonate promote the pore structure refinement and consequently reduce carbon dioxide penetration both in case of mortars containing OPC and SCM-based mortars. The most significant reduction in carbonation depth can be observed in mortars containing SC where a reduction of about $60 \%$ respect to mortar without admixtures can be found. On the contrary, accordingly with the MIP measurements, the addition of LC or blends SC-LC led to lower benefits, in the order of $30-40 \%$ reduction of the $\mathrm{CO}_{2}$ penetration depth.

Nevertheless, although the admixtures of lithium carbonate and sodium carbonate give a beneficial effect on carbonation of CSA-based mortars, these systems are still characterized by a very high value of carbonation with respect to traditional mortars manufactured with Portland cement in which the carbonation depth is generally lower than $1 \mathrm{~mm}$ after 150 days.

\section{Conclusions}

In this paper, the influence of lithium carbonate and sodium carbonate in CSA-based mortars manufactured with SCMs replacing OPC was investigated in terms of fresh properties, mechanical strength, water absorption, free shrinkage and natural carbonation. The following conclusions were made according to the results of the present paper: 
- SC and LC act as accelerator admixtures in CSA-based mortars independent of the nature of the binder employed, promoting a remarkable pore structure refinement and an improvement in elasto-mechanical properties at early age, especially by using SC;

- LC strongly reduces the workability and the pot life of mortars, compromising the possible utilization in the construction site. On the contrary, SC ensures a workability and a pot life similar to mortars manufactured without hardening accelerating admixtures;

- The SC-based mortars were characterized by a less porous binder matrix and a lower water absorption coefficient $(-25 \%)$ with respect to those of LC-based or no-admixed mortars, regardless of the binder used;

- The use of LC, alone or with SC, increased the free shrinkage of both TM and SMs up to $100 \%$ while the addition of $\mathrm{SC}$ reduced the shrinkage up to $50 \%$;

- A $60 \%$ reduction in carbonation depth can be observed in mortars containing SC respect to mortar without admixtures while the addition of LC or blends SC-LC led to lower benefits, ranging from $30 \%$ to $40 \%$;

- The SC is the most suitable additive because increased the compressive strength, reduced the shrinkage, reduced the water adsorption coefficient and reduced the carbonation depth of CSA-based mortars.

Author Contributions: All the authors contributed in equal part to conceptualization of the research, carrying out of tests and writing of the paper. All authors have read and agreed to the published version of the manuscript.

Funding: This research received no external funding.

Acknowledgments: The authors would like to acknowledge Raffaele Cioffi (University Parthenope of Naples) for the support in the experimental tests to determine the porosity of the mortar and Eng. Dalila Quartararo for carrying out the elasto-mechanical tests and carbonation measurements.

Conflicts of Interest: The authors declare no conflict of interest.

\section{References}

1. Barcelo, L.; Kline, J.; Walenta, G.; Gartner, E. Cement and carbon emissions. Mater. Struct. 2014, 47, 1055-1065. [CrossRef]

2. Schneider, M.; Romer, M.; Tschudin, M.; Bolio, H. Sustainable cement production-present and future. Cem. Concr. Res. 2011, 41, 642-650. [CrossRef]

3. Coppola, L.; Coffetti, D.; Crotti, E.; Gazzaniga, G.; Pastore, T. An Empathetic Added Sustainability Index (EASI) for cementitious based construction materials. J. Clean. Prod. 2019, 220, 475-482. [CrossRef]

4. Rahman, A.; Rasul, M.G.; Khan, M.M.K.; Sharma, S. Recent development on the uses of alternative fuels in cement manufacturing process. Fuel 2015, 145, 84-99. [CrossRef]

5. Horsley, C.; Emmert, M.H.; Sakulich, A. Influence of alternative fuels on trace element content of ordinary portland cement. Fuel 2016, 184, 481-489. [CrossRef]

6. Miller, S.A. Supplementary cementitious materials to mitigate greenhouse gas emissions from concrete: Can there be too much of a good thing? J. Clean. Prod. 2018, 178, 587-598. [CrossRef]

7. Coppola, L.; Coffetti, D.; Crotti, E. Plain and ultrafine fly ashes mortars for environmentally friendly construction materials. Sustainability 2018, 10, 874. [CrossRef]

8. Candamano, S.; De Luca, P.; Frontera, P.; Crea, F. Production of Geopolymeric Mortars Containing Forest Biomass Ash as Partial Replacement of Metakaolin. Environments 2017, 4, 74. [CrossRef]

9. Mobili, A.; Giosuè, C.; Corinaldesi, V.; Tittarelli, F. Bricks and Concrete Wastes as Coarse and Fine Aggregates in Sustainable Mortars. Adv. Mater. Sci. Eng. 2018, 2018, 8676708. [CrossRef]

10. Coppola, L.; Lorenzi, S.; Marcassoli, P.; Marchese, G. Concrete production by using cast iron industry by-products|Impiego di sottoprodotti dell'industria siderurgica nel confezionamento di calcestruzzo per opere in c.a. e c.a.p. Ind. Ital. Cem. 2007, 77, 748.

11. Carabba, L.; Manzi, S.; Rambaldi, E.; Ridolfi, G.; Bignozzi, M.C. High-temperature behaviour of alkali-activated composites based on fly ash and recycled refractory particles. J. Ceram. Sci. Technol. $2017,8,4416$. 
12. Coppola, L.; Coffetti, D.; Crotti, E. Pre-packed alkali activated cement-free mortars for repair of existing masonry buildings and concrete structures. Constr. Build. Mater. 2018, 173, 111-117. [CrossRef]

13. Marroccoli, M.; Montagnaro, F.; Telesca, A.; Valenti, G.L. Environmental implications of the manufacture of calcium sulfoaluminate-based cements. In Proceedings of the Second International Conference on Sustainable Construction Materials and Technologies, Ancona, Italy, 28-30 June 2010; Volume 1, pp. 625-635.

14. Coppola, L.; Coffetti, D.; Crotti, E.; Pastore, T. CSA-based Portland-free binders to manufacture sustainable concretes for jointless slabs on ground. Constr. Build. Mater. 2018, 187, 691-698. [CrossRef]

15. Telesca, A.; Marroccoli, M.; Pace, M.L.; Tomasulo, M.; Valenti, G.L.; Monteiro, P.J.M. A hydration study of various calcium sulfoaluminate cements. Cem. Concr. Compos. 2014, 53, 224-232. [CrossRef]

16. Pelletier, L.; Winnefeld, F.; Lothenbach, B. The ternary system Portland cement-calcium sulphoaluminate clinker-anhydrite: Hydration mechanism and mortar properties. Cem. Concr. Compos. 2010, 32, 497-507. [CrossRef]

17. Tian, H.; Kong, X.; Cui, Y.; Wang, Q.; Wang, D. Effects of polycarboxylate superplasticizers on fluidity and early hydration in sulfoaluminate cement system. Constr. Build. Mater. 2019, 228. [CrossRef]

18. Zhang, G.; Li, G.; Li, Y. Effects of superplasticizers and retarders on the fluidity and strength of sulphoaluminate cement. Constr. Build. Mater. 2016, 126, 44-54. [CrossRef]

19. García-Maté, M.; Santacruz, I.; De La Torre, Á.G.; León-Reina, L.; Aranda, M.A.G. Rheological and hydration characterization of calcium sulfoaluminate cement pastes. Cem. Concr. Compos. 2012, 34, 684-691. [CrossRef]

20. Ma, B.; Ma, M.; Shen, X.; Li, X.; Wu, X. Compatibility between a polycarboxylate superplasticizer and the belite-rich sulfoaluminate cement: Setting time and the hydration properties. Constr. Build. Mater. 2014, 51, 47-54. [CrossRef]

21. Tan, H.; Guo, Y.; Zou, F.; Jian, S.; Ma, B.; Zhi, Z. Effect of borax on rheology of calcium sulphoaluminate cement paste in the presence of polycarboxylate superplasticizer. Constr. Build. Mater. 2017, 139, 277-285. [CrossRef]

22. Mehdipour, I.; Khayat, K.H. Effect of shrinkage reducing admixture on early expansion and strength evolution of calcium sulfoaluminate blended cement. Cem. Concr. Compos. 2018, 92, 82-91. [CrossRef]

23. Mehdipour, I.; Khayat, K.H. Enhancing the performance of calcium sulfoaluminate blended cements with shrinkage reducing admixture or lightweight sand. Cem. Concr. Compos. 2018, 87, 29-43. [CrossRef]

24. Ambroise, J.; Georgin, J.F.; Peysson, S.; Péra, J. Influence of polyether polyol on the hydration and engineering properties of calcium sulfoaluminate cement. Cem. Concr. Compos. 2009, 31, 474-482. [CrossRef]

25. Zajac, M.; Skocek, J.; Bullerjahn, F.; Ben Haha, M. Effect of retarders on the early hydration of calcium-sulpho-aluminate (CSA) type cements. Cem. Concr. Res. 2016, 84, 62-75. [CrossRef]

26. Coppola, L.; Coffetti, D.; Crotti, E. Use of tartaric acid for the production of sustainable Portland-free CSA-based mortars. Constr. Build. Mater. 2018, 171, 243-249. [CrossRef]

27. Velazco, G.; Almanza, J.M.; Cortés, D.A.; Escobedo, J.C. Effect of citric acid and the hemihydrate amount on the properties of a calcium sulphoaluminate cement. Mater. Constr. 2014, 64, 1-8. [CrossRef]

28. Péra, J.; Ambroise, J. New applications of calcium sulfoaluminate cement. Cem. Concr. Res. 2004, 34, 671-676. [CrossRef]

29. Cau Dit Coumes, C.; Dhoury, M.; Champenois, J.B.; Mercier, C.; Damidot, D. Physico-chemical mechanisms involved in the acceleration of the hydration of calcium sulfoaluminate cement by lithium ions. Cem. Concr. Res. 2017, 96, 42-51. [CrossRef]

30. Cau Dit Coumes, C.; Dhoury, M.; Champenois, J.B.; Mercier, C.; Damidot, D. Combined effects of lithium and borate ions on the hydration of calcium sulfoaluminate cement. Cem. Concr. Res. 2017, 97, 50-60. [CrossRef]

31. Coppola, L.; Coffetti, D.; Crotti, E. CSA-Based Mortars Manufactured with Tartaric Acid-Based Retarder. Spec. Publ. 2018, 329, 373-388.

32. Wang, Y.; He, F.; Wang, J.; Hu, Q. Comparison of effects of sodium bicarbonate and sodium carbonate on the hydration and properties of Portland cement paste. Materials 2019, 12, 1033. [CrossRef] [PubMed]

33. Coppola, L.; Coffetti, D.; Crotti, E. Environmentally friendly concretes manufactured with CSA cement. Spec. Publ. 2018, 326, 51.

34. Bernardo, G.; Telesca, A.; Valenti, G.L. A porosimetric study of calcium sulfoaluminate cement pastes cured at early ages. Cem. Concr. Res. 2006, 36, 1042-1047. [CrossRef] 
35. Venkateswara Reddy, V.; Sudarsana Rao, H.; Jayaveera, K.N. Influence of strong alkaline substances (sodium carbonate and sodium bicarbonate) in mixing water on strength and setting properties of concrete. Indian J. Eng. Mater. Sci. 2006, 13, 123-128.

36. Eisinas, A.; Baltakys, K.; Siauciunas, R. The effect of gyrolite additive on the hydration properties of Portland cement. Cem. Concr. Res. 2012, 42, 27-38. [CrossRef]

37. Zhang, Y.; Wang, Y.; Li, T.; Xiong, Z.; Sun, Y. Effects of lithium carbonate on performances of sulphoaluminate cement-based dual liquid high water material and its mechanisms. Constr. Build. Mater. 2018, 161, 374-380. [CrossRef]

38. Li, G.; Zhang, J.; Song, Z.; Shi, C.; Zhang, A. Improvement of workability and early strength of calcium sulphoaluminate cement at various temperature by chemical admixtures. Constr. Build. Mater. 2018, 160, 427-439. [CrossRef]

(C) 2019 by the authors. Licensee MDPI, Basel, Switzerland. This article is an open access article distributed under the terms and conditions of the Creative Commons Attribution (CC BY) license (http://creativecommons.org/licenses/by/4.0/). 